\title{
The unified model of task-specific motivation and teachers' motivation to learn about teaching and learning supportive modes of ICT use
}

\author{
Cornelis J. de Brabander ${ }^{1,2,3}$ (D) Folke J. Glastra ${ }^{1}$
}

Received: 17 April 2020 / Accepted: 17 June 2020 / Published online: 6 July 2020

(C) The Author(s) 2020

\begin{abstract}
This study explored the readiness of teachers to learn about learning and teaching supportive modes of ICT use with the lens of the Unified Model of Task-specific Motivation (UMTM). According to the UMTM readiness for action is driven by feelings of activities and thoughts about the value of consequences of activities, which both can be positive and negative, and which in turn are influenced by aspects of autonomy and competence, by social relatedness, and by subjective norm. The twofold goal of this study was to test the merits of the model in general and for ICT integration in education in particular. A sample of 282 teachers provided answers about different aspects of their motivation to learn about the two types of ICT use. There were some differences between these two types of learning activities, but for both, thoughts about the value of the consequences of the activities were more important than feelings about them. Furthermore, although sense of competence was relatively more important for leaning about learning supportive ICT use than for learning about teaching supportive ICT use, teachers' sense of autonomy, a variable that is completely ignored in research on ICT integration, was in general far more important for learning about ICT use than sense of competence.
\end{abstract}

Keywords ICT integration · Teachers · Professional development · Motivation · Unified model of task-specific motivation $\cdot$ Attitudes

Cornelis J. de Brabander

brabander@fsw.leidenuniv.nl

1 Department of Educational Studies, Leiden University, Leiden, The Netherlands

2 Welten Institute, Open University of the Netherlands, Heerlen, The Netherlands

3 Query Informatisering, Voorhout, The Netherlands 


\section{Introduction}

The first goal of this study was to investigate the empirical merits of the Unified Model of Task-specific Motivation (UMTM) in the context of primary school teachers' professional development. Numerous theories of motivation (Boekaerts et al. 2010; Schunk et al. 2008) appear to conflict in different ways. The UMTM (Fig. 1) is an attempt to integrate existing theories on task-specific motivation and to reconcile their controversies. The UMTM was explained in depth by De Brabander and Martens (2014) and was slightly adapted by De Brabander and Glastra (2018).

The UMTM was explored in several studies of teachers' motivation for professional development (de Brabander and Glastra 2018; de Brabander and Martens 2018), and each occasion offered new perspectives. The subject in the current investigation was teachers' motivation to learn about the use of information and communication technology (ICT) in education. Currently, ICT is rapidly spreading over all sectors of society. The OECD report on the role of computers in education (OECD 2015) posits that ICT "has revolutionised virtually every aspect of our life and work" (p. 3) and points to the fact that a lack of ICT skills will severely impede citizens' participation in society, economically, socially, and culturally. For many years, schools were lagging behind, mainly because of the absence of an adequate ICT infrastructure (Goeman et al. 2015). But schools are catching up due to a steady decline of equipment prices and the spread of mobile technology (cf. the use of mobile technology, Crompton et al. 2017). Voogt et al. (2018, p. 8) identify a strong need for professional development in using ICT applications, especially "since most teachers continue to use IT primarily to support content delivery rather than to engage students in creative activities". This

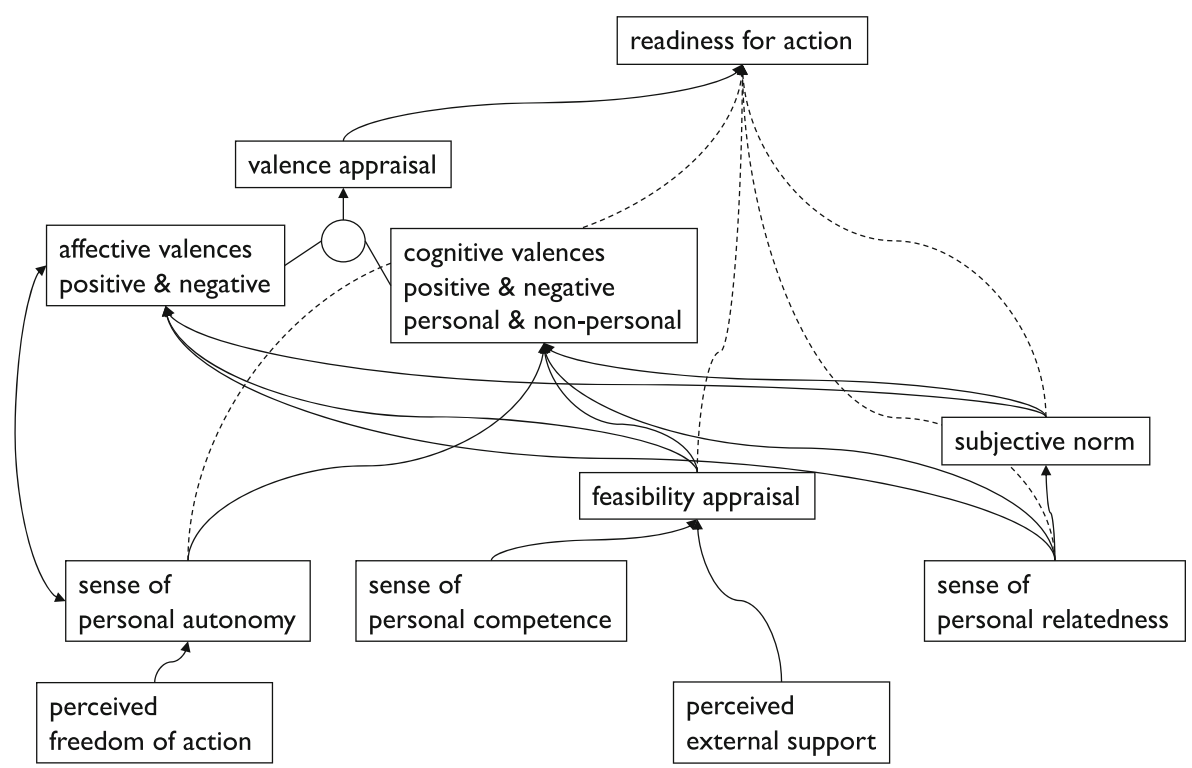

Fig. 1 The Unified Model of Task-specific Motivation (Adapted from de Brabander and Glastra 2018; de Brabander and Martens 2014) 
need for professional development prompted us to focus our exploration of the UMTM in the current study on teachers' willingness to learn about different educational ICT applications.

According to the UMTM readiness for action is driven by a specific configuration of both affective and cognitive categories of motives, called valences, which can both be positive and negative, leading to approach and avoidance motivation respectively. These valences are influenced by four task-specific antecedents: appraisals of autonomy, competence, and relatedness and subjective norm that are connected to a specific activity. Some of these antecedents are differentiated in personal and contextual facets. Investigating the motivation for specific tasks using this set of related factors promises to provide a fine-grained picture not only of the level of motivation, but also of its qualitative characteristics. As we will see when reviewing existing research on ICT integration in education, no attention is paid, for instance, to teacher autonomy. However, autonomy proved to be an important factor in teacher motivation for professional development (de Brabander and Glastra 2018; de Brabander and Martens 2018). Using the lens of the UMTM thus can improve our knowledge on ICT integration and will also clarify the relative contribution of different factors to teachers' motivation. Therefore, the second and equally important goal of this study is to explore what the Unified Model of Taskspecific Motivation can teach us about teachers' motivation to learn about the use of ICT in education.

\subsection{The unified model of task-specific motivation}

The account of the Unified Model of Task-specific Motivation given here is based on De Brabander and Martens (2014) and the adaptations proposed by De Brabander and Glastra (2018). The Model integrates several motivation theories, such as the self-determination theory (Deci and Ryan 2000), the person-object theory of interest (Krapp 2002, 2005), and several brands of expectancy*value theory, more specifically the social-cognitive theory of Bandura (1997), the expectancy-value theory of achievement motivation (Wigfield and Eccles 2000) and the theory of planned behavior (Ajzen 1991; Ajzen and Fishbein 2008). It integrates, furthermore, the distinction between approach and avoidance motivation (Elliot 2006). For the rationale behind the model we refer to De Brabander and Martens (2014) and De Brabander and Glastra (2018). The intention of the UMTM is to provide a framework of the constructs that are essentially needed to describe quantitatively and qualitatively the motivation for a rather specific course of action at a specific point in time.

De Brabander and Martens (2014) define motivation narrowly as readiness for action: a certain level of willingness to execute an activity. They posit that this readiness for action is influenced by a valence appraisal that represents the overall attractiveness of an activity, in which positive and negative, cognitive and affective valences combine on a common scale. Affective valences were defined as feelings that the actor experiences in connection with a specific course of action. Cognitive valences were defined as thoughts about the value of consequences of performing an activity. Affective and cognitive valences originate from different systems of behavior regulation: affective valences are 
brought about in an automatic and unintentional reaction on an action 'object', cognitive valences are produced by active and willful reflection by the actor (de Brabander and Martens 2014). Furthermore, cognitive valences were broken up into personal and non-personal parts. Personal cognitive valences are thoughts about the value of action consequences for the actor personally, non-personal valences are thoughts about the value of action consequences for other people than the actor. De Brabander and Martens (2014) maintain that, although generally both types of valences will covary, they are theoretically distinct categories.

De Brabander and Martens (2014) combine the distinction between affective and cognitive valences with the distinction between positive and negative valences, leading to approach and avoidance motivation (Elliot 2006), respectively. Positive valences about an activity call for entering that activity, but negative valences call for abstaining from an activity or for a counteraction that thwarts any negative effect to happen. As approach and avoidance motivation are managed by relatively distinct systems of behavior regulation (Carver 2006), positive and negative, affective and cognitive valences represent four relatively independent categories of motives. This fourfold classification offers possibilities for a more adequate analysis of motivational phenomena.

In the model proposed by De Brabander and Martens (2014) valences are affected by task-specific antecedents. They distinguish four categories: autonomy, feasibility, relatedness, and subjective norm. Autonomy refers to the origin of an action, the self or a foreign force, and is distinguished in a personal and a contextual facet. The personal facet is sense of personal autonomy and describes to what extent the actor experiences himself of herself as the originating force that drives performance of an activity. The contextual facet is perceived freedom of action which describes to what degree the actor sees options to decide about choice and execution of an activity. For De Brabander and Martens (2014) perceived freedom of action has a conditional quality: perceived freedom of action is important in so far as it influences sense of personal autonomy. Feasibility appraisal refers to the subjective probability of completing an activity successfully. Again, feasibility has a personal and contextual facet. Sense of personal competence is the subjective estimate of the actor 's resources to complete an activity with success. The contextual part is the estimate to what extent conditions in the context of an activity are conducive to a successful performance. The third task-specific antecedent is sense of personal relatedness, which is the level that the actor feels connected to the other members of the action context. Finally, De Brabander and Martens (2014) add subjective norm, which they define as the disposition to abide by normative views of important others that are relevant to the action context.

The focus on task- and time-specific motivation of the UMTM implies that many conditions and aspects remain unattended without denying their importance, though. Actual action and feedback loops from actual action are left outside the model. Also, general factors like personality traits or stable interests are not part of the model. These factors at a more aggregated level obviously influence motivation, but the model assumes that they find their expression in task-specific components. The model thus aims to provide a comprehensive snapshot of the level of motivation and its qualities 
for a rather specific course of action art a certain moment (de Brabander and Martens 2014; de Brabander and Glastra 2018).

The UMTM was empirically explored in two studies in which teachers were asked to envision they were to enter a specific professional learning activity and to evaluate all aspects of the UMTM. In a first study in which negative valences were disregarded, teachers judged three activities categorized as formal training, personal study, and reflection on practice (de Brabander and Martens 2018). The second study focused on differences in decision context by investigating professional development activities framed as chosen by the school board, the team of teachers and teachers personally (de Brabander and Glastra 2018). In both studies, the motivational data could be modeled in accordance with the UMTM, but every individual activity required its own configuration: the contribution of different components of the model depended heavily on its specific characteristics. Both studies showed for instance a larger contribution of subjective norm in social activities. Decision context mattered for the balance between affective and cognitive valences and for the relationship between personal and nonpersonal cognitive valences. In the personally chosen activity affective and cognitive valences contributed more equally to the overall valence appraisal, whereas in the not personally chosen activities cognitive valences dominated. And, not surprisingly, personal cognitive valences were more important in the personally chosen activity (de Brabander and Glastra 2018). Originally, De Brabander and Martens (2014) theorized that task-specific antecedents would influence readiness for action through valence appraisals: positive appraisals of autonomy, feasibility, relatedness and subjective norm would lead to more positive and less negative valences. The two studies (de Brabander and Glastra 2018; de Brabander and Martens 2018), however, showed that task-specific antecedents could have also direct effects on readiness for action. In all activities in both studies, sense of personal autonomy had a substantial direct influence on readiness for action and with different degrees also direct effects of other taskspecific antecedents were found. Thus, people's readiness for action may increase, just because they feel driving their action, because they see possibilities for a successful performance, because they feel connected to other participants, and because they are inclined to comply with relevant norms. Therefore, we adapted the original model with direct paths to readiness for action from all task-specific antecedents (Fig. 1).

In the current investigation we sought to contribute to the knowledge about the UMTM with a replication that may confirm the applicability of the UMTM in general and with a new set of professional learning activities that represents a different focus.

\subsection{Use of ICT applications in education}

Information and communication technology does not simply provide tools that replace older, less efficient ones, but is inextricably linked to the development of the knowledge society, which increasingly transforms both existing tools and the social context in which they are put to use. The question how this development is to be understood has given rise to an extensive debate (Castells 1996; Haunss 2013). For our purpose a global demarcation like the one given by Bell (1999) will suffice. According to Bell, knowledge in the knowledge society is the dominant principle of its production system. This dominance of knowledge has far-reaching consequences for the economy, where services become more important than goods; for the occupational structure, where 
knowledge workers replace industrial workers as the core occupational category; and for the power structure, where ownership of knowledge becomes the primary source of power instead of ownership of machinery.

In the knowledge society, education is affected like any other sector of society, but once more as a major supplier of knowledge. This triggered in the last decade much research into the integration of information and communication technology in education (e.g. Donnelly et al. 2011; Drent 2005; Goeman et al. 2015; Kreijns et al. 2013; Lin et al. 2012; Liu and Pange 2015; Sang et al. 2010; Tondeur et al. 2017a). A prevailing theme in this research is the believe that ICT applications promise an added value as they supposedly have the potential to improve education and are an important vehicle to develop the competencies needed in a knowledge society (Tubin 2006; Voogt 2010) and that teachers and their capacities are the quintessential factors in this innovation (Voogt et al. (2018), although educational practice as yet does not appear to live up to this transformational potential (Hayes 2007; OECD 2016; Smeets 2005; Tondeur et al. 2017a; cf. also Way and Webb 2007). Ottestad (2010) notes that innovative visions of science and mathematics teachers are accompanied by more traditional practices. Reviewing the domain of mathematics, Bray and Tangney (2017) also conclude that the majority of ICT applications are used to enhance traditional practice. Nevertheless, research into the role of ICT in education is trying to capture this potentially transformative nature of ICT by distinguishing between different types of use: innovative use versus traditional use (de Koster et al. 2012; Drent 2005; Maddux and Johnson 2006; Mioduser et al. 2003; Ottestad 2010; Smeets 2005); ICT use to support communication and the exchange of knowledge representations between teachers and students versus ICT use to support communications, collaboration and modelling between peers (Holmberg 2017); skill-based transmission use versus open-ended constructivist use (Niederhauser and Stoddart 2001); transmissive vs developmental (Vanderlinde et al. 2014); or, probably to appear less normative, Type I versus Type II applications (Maddux and Johnson 2006); and computers as learning tools versus computers as information tools (Tondeur et al. 2007). Analyzing the differences that are involved in this distinction, we defined these different types of use of ICT as teaching supportive versus learning supportive. This distinction is not about the kinds of applications used but about the function they have in the teaching-learning process. Teaching supportive use of ICT was defined as the use of ICT to supplement or modernize the teacher's teaching arsenal. Learning supportive ICT use was defined as the use of ICT to promote active and collaborative learning.

Factors that according to the literature on integration of ICT applications in education influence teachers' ICT use are teachers' self-efficacy, perceived usefulness, perceived ease of use, teaching beliefs, and attitude to ICT (Petko 2012; Siddiq et al. 2016). In different studies, however, their theoretical underpinning is quite different. Sometimes all of these factors are subsumed under the umbrella of teacher beliefs (Ertmer 2005). On other occasions the notion of beliefs is reserved for beliefs about teaching and learning, which is still a broad area allowing for different interpretations (see par. 1.2.3).

\subsubsection{Competence}

Self-efficacy is in some studies understood as a general construct (Joo et al. 2018; Teo 2011), whereas in others it is treated as an ICT-specific concept (Kreijns et al. 2013; 
Scherer et al. 2015; Smeets 2005; Tondeur et al. 2017b) or both as a general and an ICT-specific concept (Sang et al. 2010; Vanderlinde et al. 2014). Factors that more or less escape from this theoretical mix-up, are perceived usefulness and ease of use as employed in the Technology Acceptance Model (Joo et al. 2018). Taken together, notions that are connected to competence dominate the research scene (see also Starkey 2019). That applies to studies that use the concept of self-efficacy, whether as a general or as ICT-specific competence, but also to ease of use, which appears as a characteristic of the ICT application used, but is obviously dependent on the ICT competencies of the user. Furthermore, a popular model in research on ICT integration in education is the Technological, Pedagogical and Content Knowledge framework (TPACK) introduced by Mishra and Koehler (2006) and reviewed by Voogt et al. (2013). A search for "TPACK" in all fields of the Web of Science database in October 2019 returned 570 entries dating back to 2008. TPACK provides a taxonomy of teacher knowledge built from technological, pedagogical, subject content knowledge and their intersections. Intersections define types of knowledge where different categories overlap. For instance, the intersection between technological and content knowledge (TCK) is knowledge about the use technology to represent/research and create content in different ways without consideration about teaching. For further clarification see, for instance, Chai et al. (2013). What is relevant here, is that this body of research on knowledge aspects corroborates the claim that competence represents the most important focus in research on technology integration in education. The obvious conclusion of this research is that competence is an essential condition for technology integration (e. g. Chai et al. 2013; Joo et al. 2018).

\subsubsection{Attitude}

Attitude is also understood in a number of different versions. Some researchers define attitude as a preference for ICT, again either in general (Hermans et al. 2008; van Braak and Goeman 2003), specifically for ICT in education (Agarwal and Karahanna 2000; Player-Koro 2012; Teo 2011; Tondeur et al. 2017b) or both (Tondeur 2007; van Braak et al. 2004). Some interpretations focus on affective aspects (Agarwal and Karahanna 2000), while other interpretations of attitude, explicitly or judging by their operationalizations fall under the umbrella of expectancy*value theory which would imply the conception of attitude as a valuation of consequences (Vroom 1964) of ICT use in education (Kreijns et al. 2013; Nachmias et al. 2010; Petko 2012; Player-Koro 2012; Sang et al. 2010). A curious example of the indeterminacy of theoretical positions is found in a study by Teo (2011), where attitude was defined as the extent of having positive feelings about using technology, although the concept was explicitly based on the Theory of Planned Behavior (Ajzen 1991) and one would expect attitude to be defined accordingly as a valuation of consequences of using technology. Most studies, however, do not bother very much about the theoretical foundation of their attitude concept and create space in their conception of attitude for both affective and cognitive aspects. The Computer Attitude Questionnaire (Knezek et al. 1998, in a study of students also used by Bovée et al. 2007), for instance, is built from three subscales: Computer Importance, Computer Enjoyment, and Computer Anxiety. Van Braak and Goeman (2003) 
include items about computer liking, computer anxiety and computer confidence, thereby incorporating also notions of competence (see also Tondeur 2007). Tondeur et al. (2017b) use even a scale "that includes a broad spectrum of dimensions such as usefulness, ease of use, interest, and pleasure" (p. 49). In general, attitude positively influences ICT use or intention to use ICT in education, however, what this conclusion actually means remains unclear given the conceptual diversity of the attitude construct.

\subsubsection{Beliefs}

The topic of teacher beliefs on the one hand shows an abundant diversity, but on the other a remarkable consensus. Beliefs can refer to any cognition of teachers that might be related directly or indirectly to ICT integration. Thus, beliefs can refer to thoughts about the usefulness of ICT, to thoughts about one's ability to handle ICT applications, to thoughts about teaching, and to thoughts about learning (Ertmer 2005). In addition to thoughts about teaching and learning, Hammond (2011) distinguished beliefs about knowing. Voogt et al. (2013) refer to beliefs about technology and pedagogical beliefs. Uerz et al. (2018) reviewed studies on ICT integration among teacher educators and found nine studies (out of 26) considering beliefs about teaching and learning. Three studies were about beliefs on benefits of ICT use, six about beliefs on changes towards a more student-centered pedagogy.

But, as noticed above, there exists also a remarkable consensus among researchers as the majority of the research into teacher beliefs focusses on pedagogical beliefs and more specifically on beliefs about learner- versus teacher-centered education (e.g. Hammond 2011; Hermans et al. 2008; Koh et al. 2015; Lim and Chai 2008; Lin et al. 2012; Sang et al. 2010; Sang et al. 2011; Way and Webb 2007). Mama and Hennessy (2013) categorize teacher beliefs according to beliefs about usefulness of ICT use under which also was subsumed encouraging "constructivist instead of traditional teaching" and "autonomous learning" (p. 383). Other authors do not explicitly refer to constructivist frameworks, but use related terms like "powerful learning environments" (Smeets 2005), "traditional" versus "lifelong learning goals" (Voogt 2010), or endorsement with traditional goals, lifelong learning goals, and connectedness goals (Ottestad, 2010). The results of this research led to the conclusion that traditional and constructivistic beliefs are at least relatively independent, that high positions on both are related to higher levels of ICT use and that strong constructivistic stances can be related to specific types of ICT use like information retrieval (Tondeur et al. 2008a; Tondeur et al. 2017c; Voogt 2010).

Philosophically, constructivism entails essentially a view about knowledge and knowledge creation: knowledge about the objective world is always a human and a social construction. This epistemological stance forms a foundation from which it is possible to derive guidelines about how knowledge should be acquired, such as high levels of student autonomy and collaboration between students. In agreement with this line of reasoning Hammond (2011) designated beliefs about knowing as core beliefs and beliefs about teaching and learning as peripheral beliefs. However, this definition relies 
on the questionable assumption that teachers are skilled, deductive philosophers. Jacobson et al. (2010) showed empirically that beliefs about learning rather than epistemic beliefs shape pedagogical practices including technology use. It is therefore safer to assume that teachers have thoughts about teaching and learning without necessarily explicating their epistemological premises, and indeed, the operationalization of beliefs about teaching and learning generally are rather limited to thoughts about pedagogical practices like allowing students to work independently, involving them in setting own goals, soliciting for ideas of students, and fostering collaboration between students (Sang et al. 2010). Such thoughts can be handled by teachers within a framework of proper teaching and learning practices and do not require an epistemological explanation. The label of constructivistic beliefs, therefore, suggests a deeper level of thinking than is warranted for.

\subsubsection{Comprehensive approaches}

Scherer et al. (2015) and Teo (2011, TAM) propose to a comprehensive approach in studying ICT integration in education, but differ in what factors to take into account (cf also Vanderlinde et al. 2014, 2015). The UMTM supports actually such a view but from an integrative conception of motivation. This led both to the inclusion of new aspects not encountered in the research on ICT integration, but also to exclusion of others. In the tradition of the TAM, but with respect to technology acceptance in general, Venkatesh et al. (2003) developed an integrative model named, UTAUT that has some similarities with the UMTM. UTAUT stands for the Unified Theory of Acceptance and Use of Technology and distinguishes three conditional factors: performance expectancy, effort expectancy, and social influence. Behavioral intention mediates their influence on use behavior. A fourth conditional factor, facilitating conditions, directly influences use behavior. These concepts have some resemblances with UMTM components: performance expectancy is related to (positive) cognitive valences, effort expectancy to feasibility, but also to negative cognitive valences, social influence to subjective norm, behavioral intention to readiness for action and facilitating conditions to perceived external support. Furthermore, UTAUT defines also moderating factors like gender, age, experience, and voluntariness of use. This last factor is related with the autonomy aspects of the UMTM. The other three are task-unspecific aspects. Tondeur et al. (2008b) also recommend a multidimensional approach, but use an onion model, with type of computer use in classrooms in the center, in ever widening circles surrounded by cultural teacher characteristics, structural teacher characteristics, cultural school characteristics, and contextual school characteristics. As important cultural teacher characteristics were identified computer attitude, teachers' willingness to change, and educational beliefs (traditional beliefs and constructivistic beliefs). Structural teacher characteristics were gender and age. Important cultural school characteristics appeared to be school innovativeness and ICT support; structural characteristics were different aspects of ICT infrastructure. Some of the school characteristics were measured by questioning the ICT coordinator, but the majority of measurements were teacher perceptions. 


\subsubsection{The UMTM lens}

The UMTM represents an enrichment of ICT integration research by adding two aspects of autonomy, namely sense of personal autonomy and perceived freedom of action. In all studies on professional development motivation of teachers, autonomy was an important factor (de Brabander and Glastra 2018; de Brabander and Martens 2018). In ICT integration research teacher autonomy is completely ignored. Also, subjective norm is seldomly taken into account (Kreijns et al. 2013; Teo 2011). Secondly, the UMTM brings many aspects that have been studied separately in different investigations together in one model. Thus, it becomes possible to analyze the relative contribution of different components and to distinguish between direct and indirect effects.

However, the UMTM is also rather restrictive by focusing on task-specific motivation. The model only takes task-specific factors in account. The UMTM does not describe motivation for ICT integration in general but examines specific ICT-related activities. In this study, professional learning activities on using educational ICT applications were selected as target activities. All components of the model were assessed with respect to this target. The question on autonomy does not refer to autonomy on using ICT in general, but to sense of personal autonomy and perceived freedom of action with respect to a specific professional learning activity on ICT use. Questioning sense of personal competence is not about ICT competence in general, but with respect to a specific professional learning activity on ICT use. This task-specificity applies to all components of the model. Using the UMTM, thus implies a severe restriction. The fact that we refrained from measuring sense of personal relatedness counts as an example of this restriction. Participants were asked to imagine that they would take part in a specific learning activity. And as they, at the moment of appraisal, did not know with whom they would take part in that activity, it was impossible for them to give any meaningful appraisal of their relatedness with fellow participants. Obviously, this is not to say that all task-general aspects like computer attitude, educational beliefs, innovativeness or, for that matter, relations with colleagues are unimportant. However, in this study, it is our aim to be as complete as necessary at the task-specific level. It is the ambition of the UMTM to give a complete account of all task-specific aspects of motivation at a certain point in time. Given that account, it is assumed that higher level factors will be reflected in the components of the model and that only then it will become possible to adequately explain that motivation with factors at higher and more stable levels like cultural and structural characteristics of teachers, of the school and of the wider social context. And thereby it is important to keep the level in mind at what level these factors play their role.

Research questions Our first objective was to investigate the evidence in support of the UMTM. Secondly, we were interested in how the UMTM could help to understand the factors that influence ICT integration in education. The application of the model was guided by two heuristic questions. Given a description of two imaginary professional learning activities, differing in type of ICT use addressed, namely teaching supportive ICT use and learning supportive ICT 
use, (1) to what extent is it possible to model the motivational data provided by teachers on these imaginary activities in accordance with the UMTM, and (2) do the different activities require different models and, if so, in what respect do these models differ? The answers to these questions will also provide the ingredients for a judgement of the contribution of the UMTM to our knowledge on ICT integration in education.

\section{Method}

\subsection{Sample}

The sample was a convenience sample of 282 teachers, 233 female and 49 male, from 34 primary schools. Mean age was 39.39 years $($ S.D. $=12.11)$. The age distribution, however, was multimodal with the highest peak at 28 years approximately and some other peaks, though at a much lower level from age 40 and up. Mean number of years of experience was $14.39 \quad($ S.D. $=11.03)$,

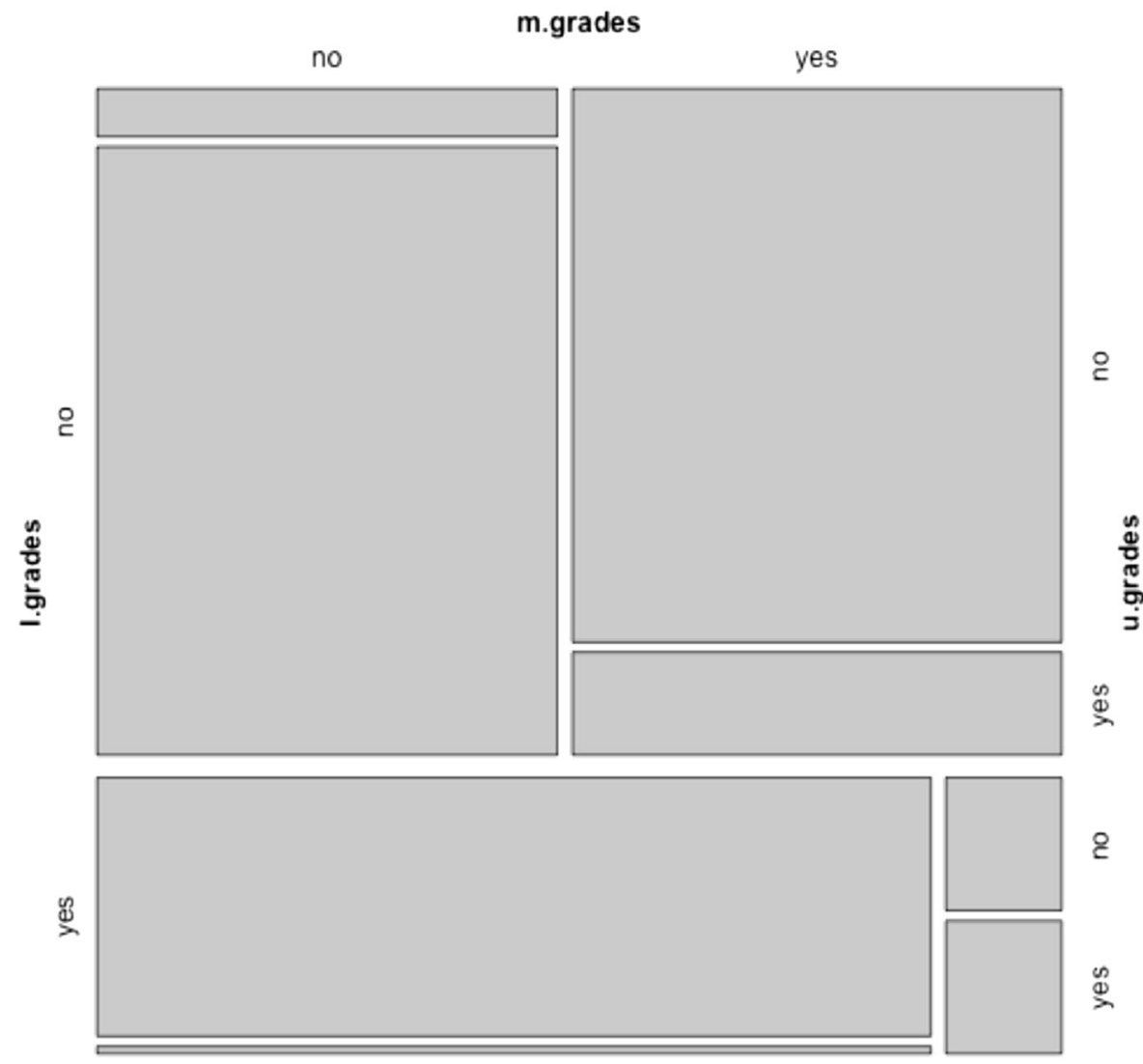

Fig. 2 Distribution of teachers over grade categories; 1.grades = grade 1 and 2 (Kindergarten); m.grades = grade 3,4 , and 5 ; u.grades $=$ grade 6,7 , and 8 
again with a multimodal distribution with the highest peak at 8 years of experience. Of the 271 teachers who reported their appointment size $(M=0.8$ full-time equivalents, S.D. $=0.24), 114(42 \%)$ had a full-time appointment $(40 \mathrm{~h})$. Relatively more common part-time appointment sizes centered around $0.4,0.6$, and 0.8. Figure 2 describes the distribution of the sample over grade levels. It shows that 280 teacher reported on the levels they taught of which 70 teachers taught exclusively in grade 1 or/and 2 (Kindergarten), 86 teachers exclusively in grade 3, 4 or/and 5, and 89 teachers exclusively in grades 6, 7 or/and 8 .

\subsection{Variables}

All components of the UMTM (except sense of personal relatedness) were translated into a single question with a bipolar seven-point scale (Table 1). For reasons set out above, sense of personal relatedness was discarded The items on positive and negative cognitive valences were differentiated into three items according to the intended recipient of these valences: the actor personally (personal positive and negative cognitive valence, respectively, ppcv and pncv), the students (students' positive and negative cognitive valence, respectively, spcv and sncv) or the school as an institution (institutional positive and negative cognitive valence, respectively, ipcv and incv). This was accomplished by interposing three scales between the two poles that were labeled "for me personally", "for the student", and "for the school". A short explanation of their meaning preceded the items on affective and cognitive valences.

This set of questions was administered two times, once for each of two professional learning activities. Teachers were asked how they would appreciate these imaginary activities. Each activity was described as a training course on how to use ICT in the classroom, which would take place in the very near future. The two activities differed with respect to the type of ICT use. The first course was about teaching supportive ICT use, the second about learning supportive ICT use. The two activities were introduced as follows:

"A professional development agency offers a course to expand the opportunities to use the interactive whiteboard in teaching practice for illustrations of subject matter, for quizzes and tests, enrich video's with explanations by the teacher and with questions for the student, etc. This course promises you to be able to save a considerable amount of time because tools and illustrations are readily available on the Internet and because you can save your lessons for future use."

"An educational guidance agency offers a course and writes about it: ICT is about more than developing and arranging digital learning material alone. ICT lends itself to support of active and collaborative learning. Developments like web 2.0, a.o. wiki's and blogs and learning platforms like Itslearning and MOOC's provide new possibilities. To employ these tools requires the teacher to be a coach for his or her students. This course will help teachers implement a rearrangement of teaching methods in which students do the learning including assessments at home with the aid of ICT and to devote classroom time to exercise (so-called 'flipping the classroom')." 
Table 1 Items on the UMTM variables (translated from Dutch)

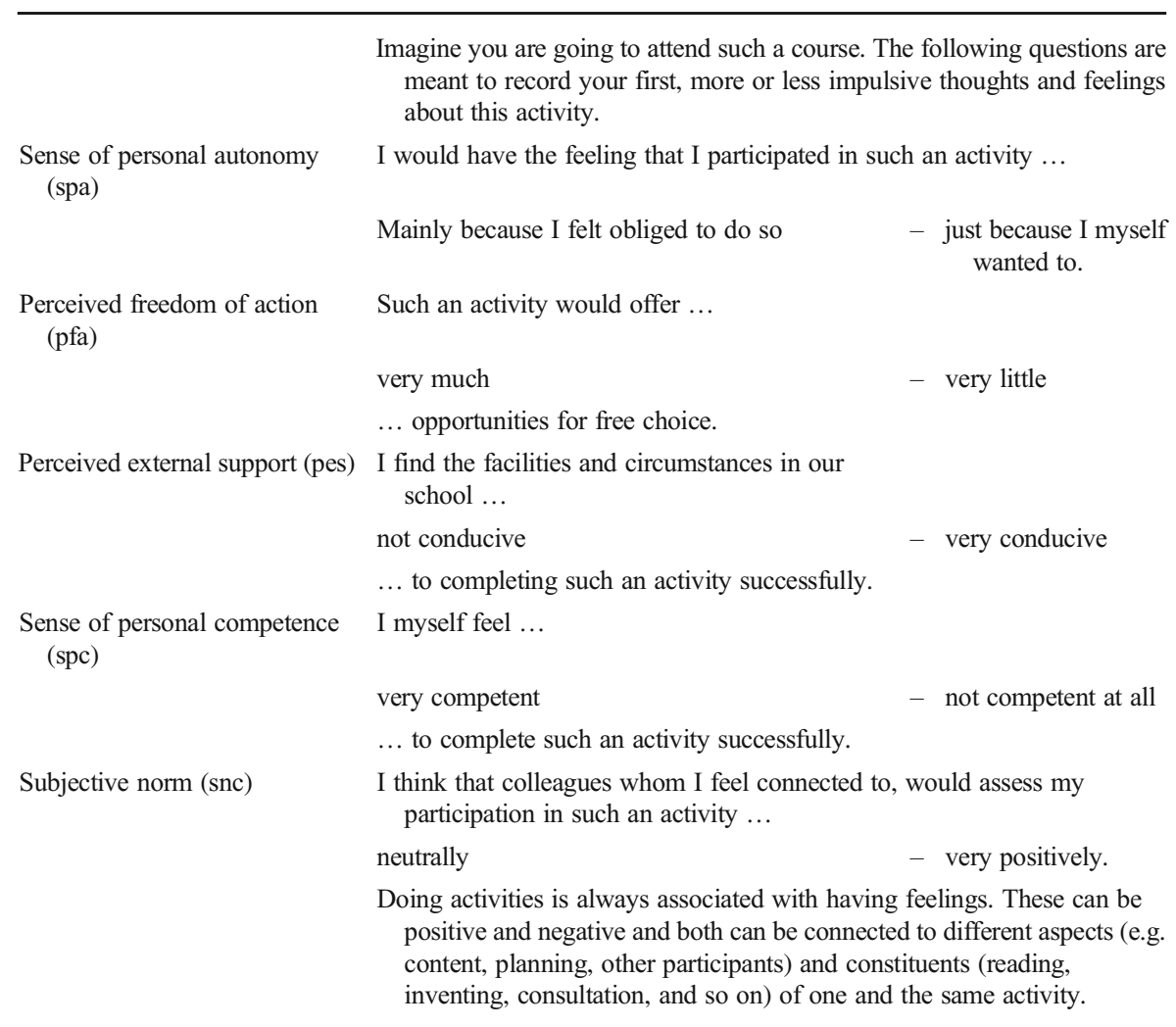

Positive affective valences (pav) During preparation and execution of such an activity I would have ... very often
- seldom or never

... a positive feeling.

Negative affective valences (nav)

Positive cognitive valences (p-pcv, s-pcv, i-pcv)
During preparation and execution of such an activity I would have ...

seldom or never

- very often

... a negative feeling.

The next question tries to determine to what extent such an activity in your eyes could lead to positive returns. With returns you can think of anything and everything: what you learn from it; interesting contacts you make; appreciation that you experience from colleagues and / or managers; you are out there, etc. In addition, we make a distinction as to who or what would benefit from this revenue, and we ask you to indicate how rewarding you would find all of this together, not only for yourself, but also for the student and for the school.

Considering the positive consequences, such an activity would be ...

barely profitable

- very profitable.

On the negative side of the balance sheet are the burdens and unwanted consequences associated with such an activity. On the one hand, there are of course all sorts of costs (money, effort, time, your replacement, lesson loss) that accompany the preparation and execution of this activity. On the other hand, such an activity may have unforeseen negative 
Table 1 (continued)

\begin{tabular}{ll}
\hline & $\begin{array}{c}\text { consequences (for example, an undesirable change in tasks). Here, too, } \\
\text { we make a distinction between who and what are the burdens and } \\
\text { negative consequences and we ask you to indicate how burdensome you } \\
\text { assess them for yourself, for the student, and for the school. }\end{array}$ \\
$\begin{array}{l}\text { Negative cognitive valences } \\
\text { (p-ncv, s-ncv, i-ncv) }\end{array}$ & $\begin{array}{l}\text { To my estimate the burdens and any unwanted consequences would be ... } \\
\text { readiness for action (rfa) }\end{array}$ \\
& $\begin{array}{l}\text { If such an activity was about to take place, I } \\
\text { would be willing to invest ... } \\
\text { very little }\end{array}$ \\
$\ldots$ effort in it.
\end{tabular}

\subsection{Procedures}

All data were collected in the context of a course Educational Research. Students Educational Sciences recruited 10 respondents using resources available to them. For the collection of the quantitative data respondents received a link to an online questionnaire. As part of their requirements, the students also conducted 2 interviews with selected respondents about their experiences with two examples of professional development activities on ICT use that the teachers attended. The interview guide was based on the questionnaire. The resulting 56 interviews were recorded on tape and transcribed. Though the lack of experience of the students may have compromised the quality of the interview data, they nevertheless were helpful in the interpretation of our quantitative outcomes.

\subsection{Analysis}

The relations between the components of our theoretical model were analyzed with structural equation modeling. In the first step confirmatory factor analysis established whether the two professional learning activities were distinct as hypothesized. In the second step a process of model generation (Kline 2011, p. 8) was employed to differentiate the two models based on residual covariances, Lagrange Multiplier tests, and Wald tests. These analyses were implemented with EQS (Bentler 2008). In every case robust maximum likelihood was used as estimation method because many of our variables did not satisfy normality assumptions.

\section{Results}

\subsection{Descriptive statistics}

In Table 2 the distribution characteristics of the components of the UMTM were collected (cf. also Table 1). Higher scores represent a higher level of the variable involved. 
Table 2 Descriptive statistics of all UMTM variables for teaching supportive and learning supportive ICT use

\begin{tabular}{|c|c|c|c|c|c|c|}
\hline & $\mathrm{N}$ & Mean & $\mathrm{SD}$ & Skewness & Kurtosis & $\mathrm{Se}$ \\
\hline \multicolumn{7}{|c|}{ Teaching supportive ICT use } \\
\hline spa & 281 & 4.77 & 1.61 & -0.69 & -0.15 & 0.10 \\
\hline pfa & 278 & 4.39 & 1.51 & -0.26 & -0.56 & 0.09 \\
\hline pes & 278 & 4.62 & 1.42 & -0.69 & 0.15 & 0.09 \\
\hline $\mathrm{spc}$ & 278 & 5.05 & 1.67 & -0.66 & -0.66 & 0.10 \\
\hline snc & 277 & 4.68 & 1.33 & -0.97 & 0.97 & 0.08 \\
\hline pav & 280 & 4.57 & 1.37 & -0.6 & -0.14 & 0.08 \\
\hline nav & 280 & 3.07 & 1.36 & 0.65 & 0.07 & 0.08 \\
\hline ppcv & 279 & 5.40 & 1.27 & -1.53 & 2.89 & 0.08 \\
\hline spcv & 279 & 5.53 & 1.25 & -1.67 & 3.55 & 0.07 \\
\hline ipcv & 278 & 5.56 & 1.19 & -1.67 & 3.91 & 0.07 \\
\hline pncv & 277 & 3.42 & 1.50 & 0.46 & -0.42 & 0.09 \\
\hline sncv & 278 & 2.82 & 1.38 & 0.64 & 0.27 & 0.08 \\
\hline incv & 276 & 3.42 & 1.40 & 0.33 & -0.40 & 0.08 \\
\hline $\mathrm{rfa}$ & 271 & 4.58 & 1.33 & -0.95 & 0.55 & 0.08 \\
\hline \multicolumn{7}{|c|}{ Learning supportive ICT use } \\
\hline spa & 277 & 3.86 & 1.79 & -0.18 & -1.14 & 0.11 \\
\hline pfa & 276 & 4.13 & 1.41 & -0.19 & -0.47 & 0.08 \\
\hline pes & 276 & 3.88 & 1.64 & -0.20 & -0.94 & 0.10 \\
\hline $\mathrm{spc}$ & 276 & 4.44 & 1.70 & -0.37 & -0.81 & 0.10 \\
\hline snc & 275 & 3.90 & 1.57 & -0.34 & -0.65 & 0.09 \\
\hline pav & 273 & 4.24 & 1.40 & -0.38 & -0.50 & 0.08 \\
\hline nav & 275 & 3.67 & 1.44 & 0.33 & -0.48 & 0.09 \\
\hline ppcv & 274 & 4.74 & 1.54 & -0.95 & 0.23 & 0.09 \\
\hline spcv & 273 & 5.04 & 1.47 & -1.11 & 0.92 & 0.09 \\
\hline ipcv & 273 & 4.94 & 1.43 & -1.09 & 0.90 & 0.09 \\
\hline pncv & 274 & 3.93 & 1.61 & 0.21 & -0.80 & 0.10 \\
\hline sncv & 274 & 3.31 & 1.48 & 0.63 & 0.09 & 0.09 \\
\hline incv & 274 & 3.75 & 1.43 & 0.47 & -0.15 & 0.09 \\
\hline $\mathrm{rfa}$ & 269 & 4.28 & 1.45 & -0.60 & -0.26 & 0.09 \\
\hline
\end{tabular}

\subsection{Differences between activities}

The distribution characteristics of the task-specific components (Table 2) revealed already some differences between the two professional learning activities. In case of learning about learning supportive ICT use spa, pfa, pes, spc and snc had lower values and positive valences were lower and negative valences were higher. Inspection of the correlations between the UMTM variables (Fig. 3) revealed higher correlations for the learning activity about learning supportive ICT use. The fit of a confirmatory factor analysis model with 14 factors under the assumption that there are essentially no differences between activities, was highly unacceptable: $\chi^{2}(N=281)=1182.586, \mathrm{df}=259, \mathrm{CFI}=.660, \mathrm{NNFI}=.504, \mathrm{RMSEA}=.113-90 \% \mathrm{CI}$ : .106-.119. Adding two factors representing the different activities improved the fit 
teaching supportive ICT use

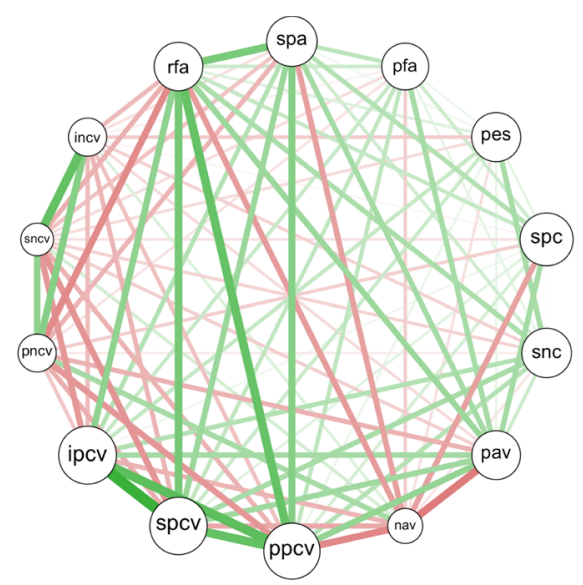

learning supportive ICT use

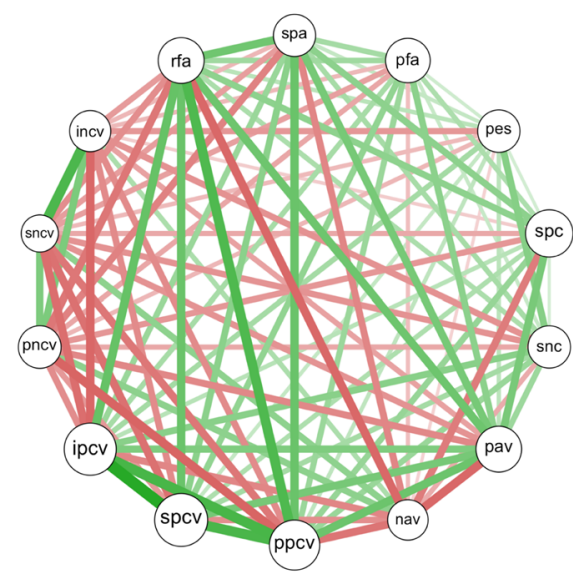

Fig. 3 Means and correlations of the UMTM variables in case of learning about teaching and learning supportive ICT use, respectively. Green lines represent positive correlations, red lines negative correlations. Thickness of the lines indicate the strength of the correlations. Circle sizes reflect relative differences between the means

considerably: $\chi^{2}(\mathrm{~N}=281)=364.909, \mathrm{df}=230, \mathrm{CFI}=.918, \mathrm{NNFI}=.950, \mathrm{RMSEA}=.046-$ 90\% CI: .037-.054. There was no correlation between the activity factors (.012). From this analysis we concluded that it was necessary to develop a separate model for each activity.

As each professional development activity was analyzed separately, the majority of components in the model was measured by one item, and consequently was represented by manifest variables. In each case we started with the relations as suggested by the UMTM. The endogenous variable in this model was readiness for action (rfa). Readiness for action was expected to be influenced by a valence appraisal (va) which was modeled as a latent variable in which 8 different valences were combined: positive and negative affective valences (pav and nav), personal positive cognitive valences (ppcv), positive cognitive valences for the school (institute, ipcv) and for the student (spcv), personal negative cognitive valences (pncv), and negative cognitive valences for the school (institute, incv) and for the student (sncv). We hypothesized that the eight types of valences were influenced by task-specific antecedents. Sense of personal autonomy influenced all valences and was in turn influenced by perceived freedom of action (pfa). In the UMTM sense of personal competence (spc) and perceived external support (pes) combine into a feasibility appraisal, however, based on their low correlation in our dataset, we treated them as separate components. The last task-specific antecedent that was expected to influence valences was subjective norm of colleagues (snc). In each analysis, we removed or added paths based on residual covariances, Lagrange Multiplier tests and Wald tests to attain two models as specialized variants of the general model. Thus, we arrived at the models that are depicted in Figs. 4 and 5. To ease the readability of these figures, the multitude of paths between taskspecific antecedents and the different valences was replaced by tables. The fit measures of both models were satisfactory. For the model on learning about teaching supportive ICT use $\chi^{2}(N=262)=46.836, \mathrm{df}=49, p=.561, \mathrm{CFI}=1.000, \mathrm{NNFI}=1.005, \mathrm{RMSEA}=.000-90 \%$ 


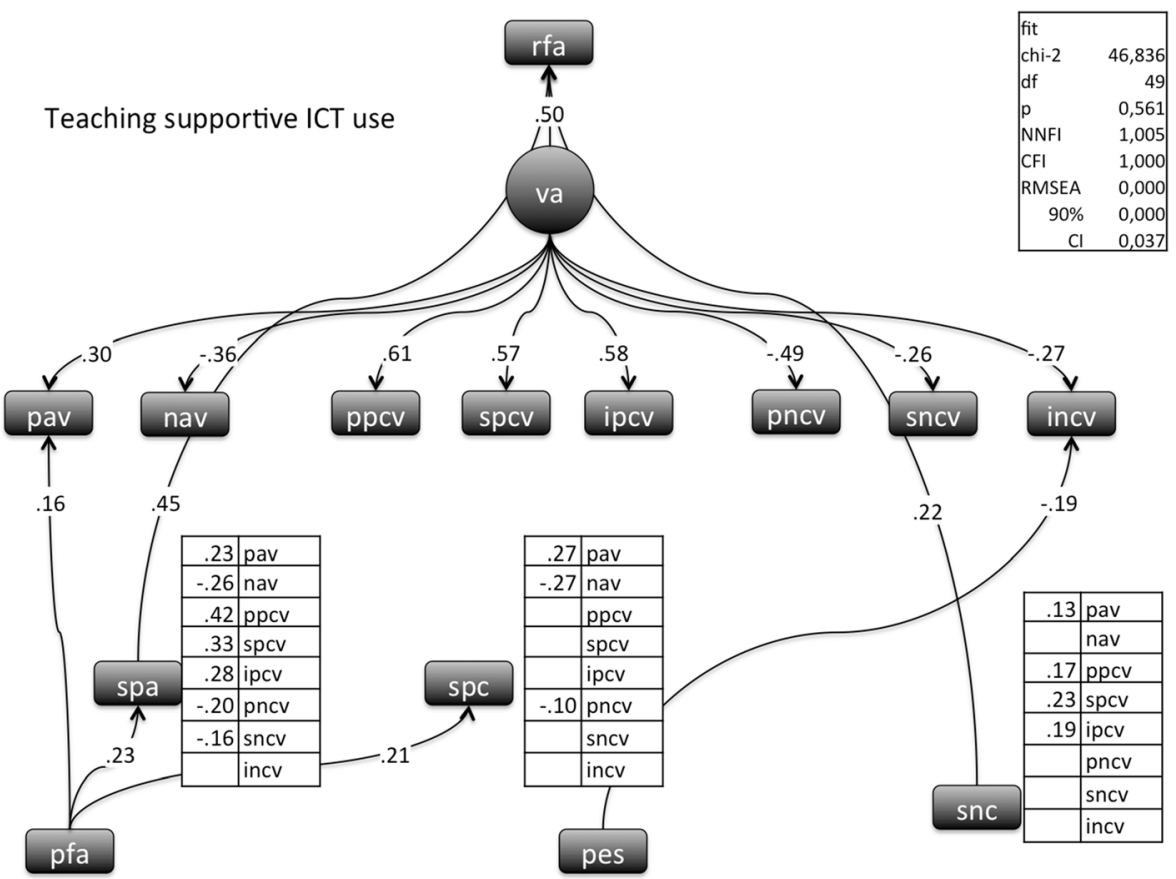

Fig. 4 Structural regression model for learning about teaching supportive ICT use. Paths from spa, spc, and snc to the valences were collected in tables

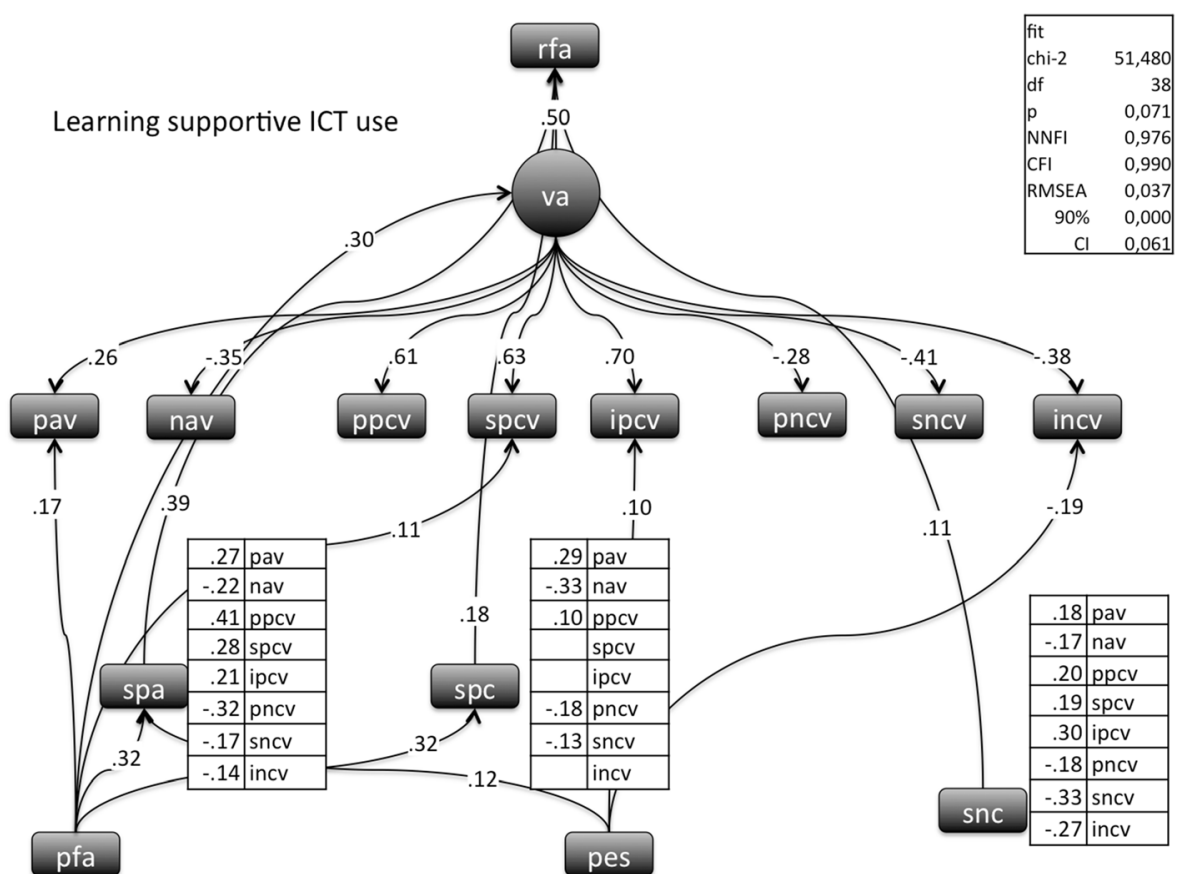

Fig. 5 Structural regression model for learning about learning supportive ICT use. Paths from spa, spc, and snc to valences were collected in tables 
Table 3 Correlated error terms in the model for learning about teaching supportive ICT use

\begin{tabular}{|c|c|c|c|c|c|c|c|c|c|c|c|c|c|}
\hline & spa & pfa & pes & $\mathrm{spc}$ & snc & pav & nav & ppcv & spcv & ipcv & pncv & sncv & incv \\
\hline spa & $*$ & & & & & & & & & & & & \\
\hline pfa & & $*$ & & & & & & & & & & & \\
\hline pes & & & $*$ & & & & & & & & & & \\
\hline $\mathrm{spc}$ & .245 & & & $*$ & & & & & & & & & \\
\hline snc & .176 & & .336 & & $*$ & & & & & & & & \\
\hline pav & & & & & & $*$ & & & & & & & \\
\hline nav & & & & & & -.308 & $*$ & & & & & & \\
\hline ppcv & & & & & & & & $*$ & & & & & \\
\hline spcv & & & & & & & & & $*$ & & & & \\
\hline ipcv & & & & & & & & .277 & .572 & $*$ & & & \\
\hline pncv & & & & & & & & & .202 & .262 & $*$ & & \\
\hline sncv & & & & & & & & & -.203 & -.251 & .311 & $*$ & \\
\hline incv & & & & & & & & & & & .424 & .524 & $*$ \\
\hline
\end{tabular}

Table 4 Correlated error terms in the model for learning about learning supportive ICT use

\begin{tabular}{|c|c|c|c|c|c|c|c|c|c|c|c|c|c|}
\hline & spa & $\mathrm{pfa}$ & pes & $\mathrm{spc}$ & snc & pav & nav & ppcv & spcv & ipcv & pncv & sncv & incv \\
\hline spa & $*$ & & & & & & & & & & & & \\
\hline pfa & & $*$ & & & & & & & & & & & \\
\hline pes & & .192 & $*$ & & & & & & & & & & \\
\hline $\mathrm{spc}$ & .354 & & & $*$ & & & & & & & & & \\
\hline snc & .198 & .211 & .468 & & $*$ & & & & & & & & \\
\hline pav & & & & & & $*$ & & & & & & & \\
\hline nav & & & & & & -.247 & $*$ & & & & & & \\
\hline ppcv & & & & & & & & $*$ & & & & & \\
\hline spcv & & & & & & & & & $*$ & & & & \\
\hline ipcv & & & & & & & & & .547 & $*$ & & & \\
\hline pncv & & & & & & & & -.237 & & & $*$ & & \\
\hline sncv & & & & & & & & & & & .201 & $*$ & \\
\hline incv & & & & & & & & & & -.188 & .284 & .567 & $*$ \\
\hline
\end{tabular}

CI: .000-.037 and for the model on learning about learning supportive ICT use $\chi^{2}(N=$ $260)=51.480, \mathrm{df}=38, p=.071, \mathrm{CFI}=.990, \mathrm{NNFI}=.976, \mathrm{RMSEA}=.037-90 \% \mathrm{CI}$ : $.000-.061$. Correlated error terms were omitted from the figures and were collected in Tables 3 and 4 . The results of these analyses are clarified under two headings: the influence of valences on readiness for action, the influence of task-specific antecedents.

\subsection{Influence of valences on readiness for action}

In Table 5 we collected for easier comparison the path coefficients of all valences from the valence appraisal factor in the two models. This table shows that in both models 
Table 5 Importance of different valences: path coefficients of valence appraisal to different valences in structural regression models for learning about teaching and learning supportive ICT use, respectively

\begin{tabular}{lcc}
\hline ICT use for: & Teaching & Learning \\
\hline pav & .30 & .26 \\
nav & -.36 & -.35 \\
ppcv & .61 & .61 \\
spcv & .57 & .63 \\
ipcv & .58 & .70 \\
pncv & -.49 & -.28 \\
sncv & -.26 & -.41 \\
incv & -.27 & -.38 \\
\hline
\end{tabular}

affective valences played a modest role and that positive cognitive valences were the most important. The two models differed with respect to the relative contribution of personal and non-personal cognitive valences. For learning about learning supportive use of ICT non-personal negative cognitive valences were more important than personal negative cognitive valences. In the model for teaching supportive ICT use the reverse was true: personal negative cognitive valences were more important than nonpersonal negative cognitive valences. And, although softened by their dominance, the same pattern was exemplified by the personal positive cognitive valences: non-personal cognitive valences gained importance in the model for learning supportive ICT use in comparison with the model for teaching supportive use.

\subsection{Influence of task-specific antecedents on valences}

Table 6 collects the path coefficients of task-specific antecedents to valences and other task-specific antecedents in the two models. In both models spa influenced all valences with a relatively high path coefficient to ppev. Spa had in both models also a substantial direct influence on rfa.

Pfa influenced in both models spa, but also spc. In the model for learning about learning supportive ICT use pfa appeared to be more important for the valences. Though path coefficients to several valences individually did not reach significance, a direct path to valence appraisal (va) in which these influences were combined, did.

In both models spc influenced the affective valences, but only in the model for learning about learning supportive ICT use spc also had a small influence on several cognitive valences. Furthermore, only in the model for learning supportive ICT use spc directly influenced rfa. In both models, pes was related negatively to incv and in the model on learning about learning supportive ICT use also positively to spa.

Snc influenced only positive valences in the model for learning about teaching supportive ICT use, but all valences in the model for learning about learning supportive ICT use. In both models snc influenced rfa directly. 
Table 6 Path coefficients of task-specific antecedents (columns) to valences and other task-specific antecedents (rows) in structural regression models for learning about teaching and learning supportive use of ICT, respectively

\begin{tabular}{|c|c|c|c|c|c|c|c|c|}
\hline \multirow[b]{2}{*}{ ICT use for: } & \multicolumn{2}{|l|}{ spa } & \multicolumn{2}{|l|}{ pfa } & \multicolumn{2}{|l|}{$\mathrm{spc}$} & \multicolumn{2}{|l|}{ snc } \\
\hline & Teaching & Learning & Teaching & Learning & Teaching & Learning & Teaching & Learning \\
\hline pav & .23 & .27 & .16 & .17 & .27 & .29 & .13 & .18 \\
\hline nav & -.26 & -.22 & & & -.27 & -.33 & & -.17 \\
\hline ppcv & .42 & .41 & & & & .10 & .17 & .20 \\
\hline spcv & .33 & .28 & & .11 & & & .23 & .19 \\
\hline ipcv & .28 & .21 & & & & & .19 & .30 \\
\hline pncv & -.20 & -.32 & & & & -.18 & & -.18 \\
\hline sncv & -.16 & -.17 & & & & -.13 & & -.33 \\
\hline incv & & -.14 & & & & & & -.27 \\
\hline va & & & & .30 & & & & \\
\hline spa & & & .23 & .32 & & & & \\
\hline $\mathrm{spc}$ & & & .21 & .32 & & & & \\
\hline rfa & .45 & .39 & & & & .18 & .22 & .11 \\
\hline
\end{tabular}

\section{Discussion}

\subsection{Interpretation of results}

In this study we measured both affective valences, which are feelings about learning to use ICT, and cognitive valences, which are valuations of its consequences. The results of our analyses showed that positive cognitive valences dominated the valence appraisal and thus had the strongest influence on readiness for action both when learning about teaching supportive ICT use and when learning about learning supportive ICT use. We may conclude, therefore, that feelings about this learning activity are less important for readiness of action than valuations of its consequences. This corroborates the strong claim of TAM-related research of the bond between perceived usefulness and use intention (Scherer et al. 2015). We found, however, a difference between the two types of learning activities related to the difference between personal and non-personal valences: non-personal cognitive valences for the student and for the school appeared more relevant when leaning about learning supportive ICT use than when learning about teaching supportive ICT use. Respondents saw somewhat more profits for the school which lent learning about learning supportive ICT a greater measure of attractiveness. In the interviews, we found several arguments about positive consequences of a collective adoption of new ICT applications: it can lead to a higher level of enthusiasm, more interaction and mutual assistance, to equalization of levels of ICT skills, to enrichment and modernization of the educational offer of the school, and, last but not least, to saving of time. However, negative cognitive valences had also an impact. Personal negative cognitive valences contributed more to the valence appraisal in the learning activity about teaching supportive use of ICT than in the activity about learning supportive ICT use. Time investment, for instance, may have been seen as a 
disadvantage of teaching supportive ICT use, whereas learning supportive ICT use seems to have been understood - presumably erroneously - as requiring more effort from the student than from the teacher. On the other hand, non-personal negative cognitive valences contributed more in the learning activity about learning supportive ICT use than in the activity about teaching supportive ICT use: learning supportive ICT use presumably was perceived as dangerous as the Internet poses numerous threats for children and was recognized as requiring more institutional resources for the infrastructure of ICT equipment than teaching supportive ICT use (cf. Scherer et al. 2015 and Petko 2012 about negative aspects of ICT integration). In the interviews, teachers mentioned underutilization of ICT among colleagues, failing equipment, and lack of time and money as bottlenecks in the adoption of ICT applications. Also, large class sizes and dangers of smartphones used freely by students were referred to, arguments that might be especially relevant for learning supportive modes of ICT use.

The role of the task-specific antecedents of valences in the two models was not supported unequivocally. Sense of personal autonomy had a clear influence on all types of valences: a higher sense of personal autonomy led to more positive and to less negative valences. Interestingly, sense of personal autonomy showed the highest influence on personal positive cognitive valences. To its importance also added the role of perceived freedom of action, which in the model for learning about teaching supportive ICT use was largely mediated by sense of personal autonomy, but also by sense of personal competence ("if I am not free to do decide on what to do and how to do it, I can't do it"). In the model for learning about learning supportive ICT use, however, the influence of perceived freedom of action on sense of personal autonomy and on sense of personal competence was slightly stronger, while it also impacted the valences: "if I am not free to do decide on what to do and how to do it, it won't do any good". And together with its direct influence on readiness for action these results account for the importance of sense of personal autonomy that we have seen also in other investigations (de Brabander and Glastra 2018; de Brabander and Martens 2018). An open question remains to what extent the central meaning of sense of personal autonomy is bound to characteristics of the teacher job. This is a significant contribution as this important role of autonomy is completely missing in research on ICT integration in education.

In both models, sense of personal competence had a moderate influence on the affective valences. But only in the model for learning about learning supportive ICT use sense of personal competence showed small influences on valences and directly on readiness for action. But all in all, we found no proof of the importance of sense of personal competence. The question is to what extent these results downplay the emphasis found in ICT integration research on competence. The UMTM also assumes a firmer role of competence appraisals. In all theories of motivation competence plays an important role in motivation and that role is well established by research. However, in one other study on the UMTM (de Brabander and Glastra 2018), the results with respect to competence were similar. Maybe, the activities proposed in our scenarios were still too abstract to enable teachers to generate an estimate of their capacity to attend the two courses successfully. The difference in familiarity between the two learning activities on ICT use in the current study might shed some light on this issue. Without doubt, learning about learning supportive ICT use was for many teachers an uncharted territory. It is conceivable that in an unfamiliar activity, thoughts about 
(in)competence trigger thoughts about - especially negative - outcomes, which they don't trigger in familiar activities and that familiarity does not affect the relation between sense of personal competence and affective valences. Also, in the 'familiar' activity the mean of personal competence was higher and its variance lower than in the 'unfamiliar' activity.

Perceived external support played a very minor role in both types of learning activities, much smaller than was assumed in the UMTM. Better support diminished expected negative consequences for the school, and had a small positive influence on sense of personal autonomy when learning about learning supportive ICT use. Again, the proposed activities may have been too imaginary for the teachers to enable them to judge the role of external support adequately.

Subjective norm had its widest influence on the valences when learning about learning supportive ICT use. The influence on the negative cognitive valence for the student and for the school stood out. The familiarity issue also affected subjective norm. Apparently, learning supportive ICT use was perceived as such a new undertaking that thoughts about support from the colleagues triggered thoughts about especially negative - consequences.

In both learning activities, we witnessed direct influences on readiness for action from the task-specific antecedents. Most notably, sense of personal autonomy directly contributed to readiness for action in both activities substantially. Subjective norm also had an impact on readiness for action, but at a lower level. To some extent teachers were willing to take part when colleagues would consent. Sense of personal competence increased readiness for action directly only when learning about learning supportive ICT use, attesting again to the newness of learning supportive ICT use. The possibility of direct effects on readiness for action of task-specific antecedents is well established (see also De Brabander and Glastra 2018; De Brabander and Martens 2018). It is still unclear how to interpret these direct effects. It is possible that people simply are ready for action when they see that other significant people support that action. But people in general (or teachers?) are to some extent also ready to act simply because they experience themselves as being the driving force and/or because they feel they can do it. Possibly, valences are not explicitly activated or remain underactivated, for instance, when actions are rather habitual in which case the level of personal autonomy and of feasibility provide enough trust that the level of affective and cognitive valences will be high enough, so that valences do not need to be activated in their own right.

\subsection{Limitations}

A small caveat regarding the interpretation of the results of this study is in order. All questions posed to the teachers were about learning about different types of ICT use. It is doubtful whether teachers strictly adhered to this narrow focus. Presumably, they broadened the topic in their answers to different types of ICT use as such. Thus, we must acknowledge the possibility that they referred to valences of teaching and learning supportive use of ICT, their competence with these types of use, and so on. This shift of focus, however, does not affect the conclusions regarding the UMTM.

Furthermore, all data were collected by means of a questionnaire. Especially, when investigating feelings, there is reason to believe that verbal reports may lead to distortion due to social desirability effects or to the omission of less conscious feelings 
(Gawronski and De Houwer 2014). This may relativize the difference in importance we have observed between affective and cognitive valences. Affective valences might prove to be more important than could be uncovered using verbal reports.

The subjects in our study responded to imaginary activities. It is possible that the overall low importance of sense of personal competence was introduced to some extent by the use of vignettes as a means to provoke motivational appraisals. Considering imaginary activities instead of actual real-life activities might make appraisals of competence for instance less compelling and thus less important. In one study using description of activities such as personal study, reflecting on practice and formal training as stimulus, De Brabander and Martens (2018) found stronger effects of feasibility aspects. Maybe these descriptions were more easily recognized as real-life activities. Investigations on appraisals of actual activities are needed to shed light on this issue.

\subsection{Implications}

This study draws attention of researchers to the role of autonomy aspects in professional development in the area of ICT applications. It shows that autonomy is a neglected aspect in research on ICT integration and that this neglect is not warranted for. Having acknowledged its importance, however, does not immediately lead to prescriptions on how to handle this aspect of teacher motivation in professional development policies. We have seen intricate configurations of the different components of the UMTM that show that in expectations of professional development about learning supportive ICT use, teachers feel strongly less autonomous, but also less competent, that they see more disadvantages for the students and the school and as a result show less readiness for action. The research literature shows that researchers on the other hand, apparently unlike teachers, have a strong favor for learning supportive ICT use. Even when we feel sympathetic with the position that learning supportive ICT use has more potential to innovate education, it might be wiser for many teachers to initially focus their professional development on learning of teaching supportive ICT use in the expectation that strengthening their feelings of autonomy and competence in the long run will make them more successful in bringing about more fundamental changes. From other research we know that the fact who actually decides about professional development activities has motivationally important implications (de Brabander and Glastra 2018).

\section{Conclusion}

All in all, we concluded that the differentiation in different types of valences, which is a hallmark of the UMTM, was strongly supported by the configuration of valences that we found in different activities. Each activity provoked a set of affective and cognitive, and positive and negative valences carrying different weights that eventually influenced readiness for action. These weights in different activities aptly demonstrated the subtle interaction between different types of valences: when learning about teaching supportive ICT use personal cognitive valences were more relevant to readiness for action, while when learning about learning supportive ICT use, non-personal cognitive valences appeared more relevant. With respect to the task-specific antecedents the account was more balanced. The influence of sense of personal autonomy, a new finding in the 
context of ICT integration, was well confirmed, but the influence of sense of personal competence, perceived external support, and subjective norm did not meet the levels expected, especially when learning about teaching supportive ICT use. The variability of these influences was found in other studies as well (de Brabander and Glastra 2018; de Brabander and Martens 2018). This study adds familiarity of activities as a possible explanation for direct effects of task-specific antecedents.

\section{Compliance with ethical standards}

Conflicts of interest/competing interests We declare that we have no conflicts of interest.

Ethics approval All procedures in this study were following strictly the ethical guidelines of the University of Leiden, The Netherlands.

Consent to participate The subjects were informed about the aims of the study. They participated voluntarily and could stop their participation at any moment during the investigation if they wished to do so. All data were anonymized before processing.

Consent for publication Not applicable.

Availability of data and material Data are available from the corresponding author.

Code availaibility Not applicable.

Open Access This article is licensed under a Creative Commons Attribution 4.0 International License, which permits use, sharing, adaptation, distribution and reproduction in any medium or format, as long as you give appropriate credit to the original author(s) and the source, provide a link to the Creative Commons licence, and indicate if changes were made. The images or other third party material in this article are included in the article's Creative Commons licence, unless indicated otherwise in a credit line to the material. If material is not included in the article's Creative Commons licence and your intended use is not permitted by statutory regulation or exceeds the permitted use, you will need to obtain permission directly from the copyright holder. To view a copy of this licence, visit http://creativecommons.org/licenses/by/4.0/.

\section{References}

Agarwal, R., \& Karahanna, E. (2000). Time flies when You're having fun: Cognitive absorption and beliefs about information technology usage. MIS Quarterly, 24, 665-694. https://doi.org/10.2307/3250951.

Ajzen, I. (1991). The theory of planned behavior. Organizational and Human Decision Processes, 50, 179211. https://doi.org/10.1016/0749-5978(91)90020-T.

Ajzen, I., \& Fishbein, M. (2008). Scaling and testing multiplicative combinations in the expectancy-value model of attitudes. Journal of Applied Social Psychology, 38, 2222-2247. https://doi.org/10.1111/j.15591816.2008.00389.x.

Bandura, A. (1997). Self-efficacy: The exercise of control. New York: W. H. Freeman \& Co..

Bell, D. (1999). The coming of the post-industrial society: A venture in social forecasting. Special anniversary edition with a new foreword by the author. New York: Basic Books [First Published 1973.].

Bentler, P. M. (2008). EQS 6 structural equations program manual. Encino: Multivariate Software, Inc..

Boekaerts, M., Van Nuland, H. J. C., \& Martens, R. L. (2010). Perspectives on motivation: What mechanism energise students' behaviour in the classroom. In K. Littleton, C. Wood, \& J. Kleine Staarman (Eds.), International handbook of psychology in education (pp. 535-568). Bingley: Emerald Group Publishing Limited.

Bovée, C., Voogt, J., \& Meelissen, M. (2007). Computer attitudes of primary and secondary students in South Africa. Computers in Human Behavior, 23, 1762-1776. https://doi.org/10.1016/j.chb.2005.10.004. 
van Braak, J., \& Goeman, K. (2003). Differences between general computer attitudes and perceived computer attributes: Development and validation of a scale. Psychological Reports, 92, 655-660. https://doi. org/10.2466/pr0.2003.92.2.655.

van Braak, J., Tondeur, J., \& Valcke, M. (2004). Explaining different types of computer use among primary school teachers. European Journal of Psychology of Education, 19, 407-422. https://oi.org/10.1007/BF03173218.

de Brabander, C. J., \& Glastra, F. J. (2018). Testing a unified theory of task-specific motivation: How teachers appraise three professional development activities. Frontline Learning Research, 6, 54-76. https://doi. org/10.14786/flr.v4i2.342.

de Brabander, C. J., \& Martens, R. L. (2014). Towards a unified theory of task-specific motivation. Educational Research Review, 11, 27-44. https://doi.org/10.1016/j.edurev.2013.11.001.

de Brabander, C. J., \& Martens, R. L. (2018). Empirical exploration of a unified model of task-specific motivation. Psychology, 9, 540-560. https://doi.org/10.4236/psych.2018.94033.

Bray, A., \& Tangney, B. (2017). Technology usage in mathematics education research - A systematic review of recent trends. Computers \& Education, 114, 255-273. https://doi.org/10.1016/j.compedu.2017.07.004.

Carver, C. S. (2006). Approach, avoidance, and the self-regulation of affect and action. Motivation and Emotion, 30, 105-110. https://doi.org/10.1007/s11031-006-9044-7.

Castells, M. (1996). The rise of the network society. The information age: Economy, society and culture (Vol. 1). Oxford: Blackwell.

Chai, C. S., Koh, J. H. L., \& Tsai, C.-C. (2013). A review of technological pedagogical content knowledge. Educational Technology \& Society, 16(2), 31-51.

Crompton, H., Burke, D., \& Gregory, K. H. (2017). The use of mobile learning in PK-12 education: A systematic review. Computers \& Education, 110, 51-63. https://doi.org/10.1016/j.compedu.2017.03.013.

Deci, E. L., \& Ryan, R. M. (2000). The "what" and "why" of goal pursuits: Human needs and the selfdetermination of behaviour. Psychological Inquiry, 11, 227-268.

Donnelly, D., McGarr, O., \& O'Reilly, J. (2011). A framework for teachers' integration of ICT into their classroom practice. Computers \& Education, 57, 1469-1483. https://doi.org/10.1016/j. compedu.2011.02.014.

Drent, M. (2005). In transitie: op weg naar ict-gebruik op de pabo [In transition: Towards innovative ict use in teacher education]. Doctoral dissertation. Enschede: University of Twente.

Elliot, A. J. (2006). The hierarchical model of approach-avoidance motivation. Motivation and Emotion, 30, 111-116. https://doi.org/10.1007/s11031-006-9028-7.

Ertmer, P. A. (2005). Teacher pedagogical beliefs: The final frontier in our quest for technology integration? Educational Technology Research and Development, 53(4), 25-39. https://doi.org/10.1007/BF02504683.

Gawronski, B., \& De Houwer, J. (2014). Implicit measures in social and personality psychology. In H. T. Reis \& C. M. Judd (Eds.), Handbook of research methods in social and personality psychology (pp. 283-310). New York: Cambridge University Press.

Goeman, K., Elen, J., Pynoo, B., \& van Braak, J. (2015). Time for action! ICT integration in formal education: Key findings from a region-wide follow-up monitor. TechTrends, 59(5), 40-50. https://doi.org/10.1007 /s11528-015-0890-6.

Hammond, M. (2011). Beliefs and ICT: What can we learn from experienced educators? Technology Pedagogy and Education, 20, 289-300. https://doi.org/10.1080/1475939X.2011.610930.

Haunss, S. (2013). Conflicts in the knowledge society. The contentious politics of intellectual property. Cambridge: Cambridge University Press. https://doi.org/10.1017/CBO9781139567633.

Hayes, D. N. A. (2007). ICT and learning: Lessons from Australian classrooms. Computers \& Education, 49, 385-395. https://doi.org/10.1016/j.compedu.2005.09.003.

Hermans, R., Tondeur, J., van Braak, J., \& Valcke, M. (2008). The impact of primary school teachers' educational beliefs on the classroom use of computers. Computers \& Education, 51, 1499-1509. https://doi.org/10.1016/j.compedu.2008.02.001.

Holmberg, J. (2017). Applying a conceptual design framework to study teachers' use of educational technology. Education and Information Technologies, 22, 2333-2349. https://doi.org/10.1007/s10639-0169536-3.

Jacobson, M. J., So, H.-J., Teo, T., Lee, J., Pathak, S., \& Lossman, H. (2010). Epistemology and learning: Impact on pedagogical practices and technology use in Singapore schools. Computers \& Education, 55, 1694-1706. https://doi.org/10.1016/j.compedu.2010.07.014.

Joo, Y. J., Park, S., \& Lim, E. (2018). Factors influencing Preservice Teachers' intention to use technology: TPACK, teacher self-efficacy, and technology acceptance model. Educational Technology \& Society, 21(3), 48-59.

Kline, R. B. (2011). Principles and practice of structural equation modeling (Third ed.). New York: The Guilford Press. 
Knezek, G., Christensen, R., \& Miyashita, K. (1998). Instruments for assessing attitudes toward information technology. Denton, TX: Texas Center for Educational Technology.

Koh, J. H. L., Chai, C. S., Benjamin, W., \& Hong, H.-Y. (2015). Technological pedagogical content knowledge (TPACK) and design thinking: A framework to support ICT lesson design for 21 st century learning. Asia-Pacific Education Researcher, 24, 535-543.

de Koster, S., Kuiper, E., \& Volman, M. (2012). Concept-guided development of ICT use in 'traditional' and 'innovative' primary schools: What types of ICT use do schools develop? Journal of Computer Assisted Learning, 28, 454 464. https://doi.org/10.1111/j.1365-2729.2011.00452.x.

Krapp, A. (2002). Structural and dynamic aspects of interest development: Theoretical considerations from an ontogenetic perspective. Learning and Instruction, 12, 383-409. https://doi.org/10.1016/S0959-4752(01 00011-1.

Krapp, A. (2005). Basic needs and the development of interest and intrinsic motivational orientations. Learning and Instruction, 15, 381-395. https://doi.org/10.1016/j.learninstruc.2005.07.007.

Kreijns, K., Van Acker, F., Vermeulen, M., \& van Buuren, H. (2013). What stimulates teachers to integrate ICT in their pedagogical practices? The use of digital learning materials in education. Computers in Human Behavior, 29, 217-225. https://doi.org/10.1016/j.chb.2012.08.008.

Lim, C. P., \& Chai, C. S. (2008). Teachers' pedagogical beliefs and their planning and conduct of computermediated classroom lessons. British Journal of Educational Technology, 39, 807-828. https://doi. org/10.1111/j.1467-8535.2007.00774.x.

Lin, J. M.-C., Wang, P.-Y., \& Lin, I.-C. (2012). Pedagogy * technology: A two-dimensional model for teachers' ICT integration. British Journal of Educational Technology, 43, 97-108. https://doi.org/10.1111 j.1467-8535.2010.01159.x.

Liu, X., \& Pange, J. (2015). Early childhood teachers' perceived barriers to ICT integration in teaching: A survey study in mainland China. Journal of Computers in Education, 2, 61-75. https://doi.org/10.1007 /s40692-014-0025-7.

Maddux, C. D., \& Johnson, D. L. (2006). Type II applications of information Technology in Education. Computers in the Schools, 23(1-2), 1-5. https://doi.org/10.1300/J025v23n01 01.

Mama, M., \& Hennessy, S. (2013). Developing a typology of teacher beliefs and practices concerning classroom use of ICT. Computers \& Education, 68, 380-387. https://doi.org/10.1016/j. compedu.2013.05.022.

Mioduser, D., Nachmias, R., Tubin, D., \& Forkosh-Baruch, A. (2003). Analysis Schema for the study of domains and levels of pedagogical innovation in schools using ICT. Education and Information Technologies, 8, 23-36. https://doi.org/10.1023/A:1023922207476.

Mishra, P., \& Koehler, M. J. (2006). Technological pedagogical content knowledge: A framework for teacher knowledge. Teachers College Record, 108, 1017-1054. https://doi.org/10.1111/j.1467-9620.2006.00684. $\mathrm{X}$.

Nachmias, R., Mioduser, D., \& Forkosh-Baruch, A. (2010). ICT use in education: Different uptake and practice in Hebrew-speaking and Arabic-speaking schools in Israel. Journal of Computer Assisted Learning, 26, 492-506. https://doi.org/10.1111/j.1365-2729.2010.00374.x.

Niederhauser, D. S., \& Stoddart, T. (2001). Teachers' instructional perspectives and use of educational software. Teaching and Teacher Education, 17, 15-31. https://doi.org/10.1016/S0742-051X(00)00036-6.

OECD. (2015). Students, Computers and Learning: Making the Connection, PISA. Paris: OECD Publishing. https://doi.org/10.1787/9789264239555-en.

OECD. (2016). Innovating education and educating for innovation: The power of digital technologies and skills. Paris: OECD Publishing. https://doi.org/10.1787/9789264265097-en.

Ottestad, G. (2010). Innovative pedagogical practice with ICT in three Nordic countries - differences and similarities. Journal of Computer Assisted Learning, 26, 478-491. https://doi.org/10.1111/j.13652729.2010.00376.x.

Petko, D. (2012). Teachers' pedagogical beliefs and their use of digital media in classrooms: Sharpening the focus of the 'will, skill, tool' model and integrating teachers' constructivist orientations. Computers \& Education, 58, 1351-1359. https://doi.org/10.1016/j.compedu.2011.12.013.

Player-Koro, C. (2012). Factors influencing teachers' use of ICT in education. Education Inquiry, 3, $93-108$. https://doi.org/10.3402/edui.v3i1.22015.

Sang, G., Valcke, M., van Braak, J., \& Tondeur, J. (2010). Student teachers' thinking processes and ICT integration: Predictors of prospective teaching behaviors with educational technology. Computers \& Education, 54, 103-112. https://doi.org/10.1016/j.compedu.2009.07.010.

Sang, G., Valcke, M., van Braak, J., Tondeur, J., \& Chang, Z. (2011). Predicting ICT integration into classroom teaching in Chinese primary schools: Exploring the complex interplay of teacher-related 
variables. Journal of Computer Assisted Learning, 27, 160-172. https://doi.org/10.1111/j.13652729.2010.00383.x.

Scherer, R., Siddiq, F., \& Teo, T. (2015). Becoming more specific: Measuring and modeling teachers' perceived usefulness of IT in the context of teaching and learning. Computers \& Education, 88, 2022014. https://doi.org/10.1016/j.compedu.2015.05.005.

Schunk, D. H., Pintrich, P. R., \& Meece, J. L. (2008). Motivation in education. In Theory, research, and applications. Upper Saddle River: Pearson Education, Inc..

Siddiq, F., Scherer, R., \& Tondeur, J. (2016). Teachers' emphasis on developing students' digital information and communication skills (TEDDICS): A new construct in 21 st century education. Computers \& Education, 92-93, 1-14.

Smeets, E. (2005). Does ICT contribute to powerful learning environments in primary education? Computers \& Education, 44, 343-355. https://doi.org/10.1016/j.compedu.2004.04.003.

Starkey, L. (2019). A review of research exploring teacher preparation for the digital age. Cambridge Journal of Education, 50, 37-56. https://doi.org/10.1080/0305764X.2019.1625867.

Teo, T. (2011). Factors influencing teachers' intention to use technology: Model development and test. Computers \& Education, 57, 2432-2440. https://doi.org/10.1016/j.compedu.2011.06.008.

Tondeur, J. (2007). Development and validation of a model of ICT integration in primary education. Doctoral dissertation. Ghent: Ghent University.

Tondeur, J., van Braak, J., \& Valcke, M. (2007). Towards a typology of computer use in primary education. Journal of Computer Assisted Learning, 23, 197-206. https://doi.org/10.1111/j.1365-2729.2006.00205.x.

Tondeur, J., Hermans, R., van Braak, J., \& Valcke, M. (2008a). Exploring the link between teachers' educational belief profiles and different types of computer use in the classroom. Computers in Human Behavior, 24, 2541-2553. https://doi.org/10.1016/j.chb.2008.02.020.

Tondeur, J., Valcke, M., \& van Braak, J. (2008b). A multidimensional approach to determinants of computer use in primary education: Teacher and school characteristics. Journal of Computer Assisted Learning, 24, 494-506. https://doi.org/10.1111/j.1365-2729.2008.00285.x.

Tondeur, J., Pareja Roblin, N., van Braak, J., Voogt, J., \& Prestridge, S. (2017a). Preparing beginning teachers for technology integration in education: Ready for take-off? Technology, Pedagogy and Education, 26, 157-177. https://doi.org/10.1080/1475939X.2016.1193556.

Tondeur, J., Scherer, R., Siddiq, F., \& Baran, E. (2017b). A comprehensive investigation of TPACK within pre-service teachers' ICT profiles: Mind the gap. Australasian Journal of Educational Technology, 33(3), 46-60. https://doi.org/10.14742/ajet.3504.

Tondeur, J., van Braak, J., Ertmer, P. A., \& Ottenbreit-Leftwich, A. (2017c). Understanding the relationship between teachers' pedagogical beliefs and technology use in education: A systematic review of qualitative evidence. Educational Technology Research and Development, 65, 555-575. https://doi.org/10.1007 /s11423-016-9481-2.

Tubin, D. (2006). Typology of ICT implementation and technology applications. Computers in the Schools, 23, 85-98. https://doi.org/10.1300/J025v23n01_08.

Uerz, D., Volman, M., \& Kral, M. (2018). Teacher educators' competences in fostering student teachers' proficiency in teaching and learning with technology: An overview of relevant research literature. Teaching and Teacher Education, 70, 12-23. https://doi.org/10.1016/j.tate.2017.11.005.

Vanderlinde, R., Aesaert, K., \& van Braak, J. (2014). Institutionalised ICT use in primary education: A multilevel analysis. Computers \& Education, 72, 1-10. https://doi.org/10.1016/j.compedu.2013.10.007.

Vanderlinde, R., Aesaert, K., \& van Braak, J. (2015). Measuring ICT use and contributing conditions in primary schools. British Journal of Educational Technology, 46, 1056-1063. https://doi.org/10.1111 /bjet.12282.

Venkatesh, V., Morris, M. G., Davis, G. B., \& Davis, F. D. (2003). User acceptance of information technology: Toward a unified view. MIS Quarterly, 27, 425-478. https://oi.org/10.2307/30036540.

Voogt, J. (2010). Teacher factors associated with innovative curriculum goals and pedagogical practices: Differences between extensive and non-extensive ICT-using science teachers. Journal of Computer Assisted Learning, 26, 453-464. https://doi.org/10.1111/j.1365-2729.2010.00373.x.

Voogt, J., Fisser, P., Pareja Roblin, N., Tondeur, J., \& van Braak, J. (2013). Technological pedagogical content knowledge - a review of the literature. Journal of Computer Assisted Learning, 29, 109-121. https://doi.org/10.1111/j.1365-2729.2012.00487.x.

Voogt, J., Knezek, G., Christensen, R., \& Lai, K.-W. (2018). Developing an understanding of the impact of digital technologies on teaching and learning in an ever-changing landscape. In J. Voogt, G. Knezek, R. Christensen, \& K.-W. Lai (Eds.), Second Handbook of Information Technology in Primary and Secondary Education (Springer International Handbooks of Education) (pp. 3-12). New York, NJ, Springer. https://doi.org/10.1007/978-3-319-71054-9_113. 
Vroom, V. H. (1964). Work and motivation. New York: Wiley.

Way, J., \& Webb, C. (2007). A framework for analysing ICT adoption in Australian primary schools. Australasian Journal of Educational Technology, 23, 559-582.

Wigfield, A., \& Eccles, J. S. (2000). Expectancy-value theory of achievement motivation. Contemporary Educational Psychology, 25, 68-81. https://doi.org/10.1006/ceps.1999.1015.

Publisher's note Springer Nature remains neutral with regard to jurisdictional claims in published maps and institutional affiliations. 